\title{
Engineering Education for Sustainable Development: The European Project Semester Approach
}

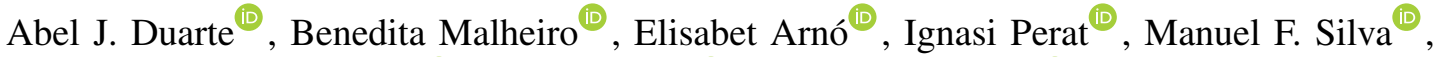 \\ Pedro Fuentes-Durá ${ }^{\circledR}$, Pedro Guedes ${ }^{\circledR}$, and Paulo Ferreira ${ }^{\circledR}$, Member, IEEE
}

\begin{abstract}
Contribution: An analysis of the extent to which sustainability is present in the syllabi, project briefs, report templates, and student final reports of the three Iberian European project semester (EPS) providers, over a five-year period.

Background: EPS is a one-semester capstone project framework that adopts project-based learning and multicultural, multidisciplinary teamwork. Educating engineers for sustainable development requires fostering critical and ethical thinking and a desire for equity, solidarity and preservation of natural resources, and cultural and genetic diversity. Existing engineering capstone design programs emphasize solving real world problems, hands-on training, and soft skills, but few focus on sustainability aspects of engineering design. The three Iberian EPS providers adopt project-based learning and teamwork methodologies, promoting the development of transversal skills and addressing sustainability in a multicultural and multidisciplinary background.

Intended Outcomes: To show that the three Iberian EPS providers follow these recommendations and contribute to raising students' awareness of sustainable development.

Application Design: The proposed sustainability learning assessment method collects evidence from syllabi, project briefs, report templates, and final reports to extract faculty and student perspectives. The sustainability-related terms collected were processed into word cloud format, allowing a simple and intuitive interpretation of students' understanding of sustainability, and in co-occurrence network format, to understand if sustainability has a pervasive or confined presence within the reports.
\end{abstract}

Manuscript received May 15, 2018; revised September 28, 2018, January 19, 2019, April 2, 2019, and June 5, 2019; accepted June 16, 2019 This work was supported in part by the European Union (FEDER funds) through Compete and in part by the National Funds through the Portuguese funding agency Fundação para a Ciência e Tecnologia under Project UID/QUI/50006/2019 and Project UID/EEA/50014/2019. (Corresponding author: Benedita Malheiro.)

A. J. Duarte is with the School of Engineering, Porto Polytechnic, 4249-015 Porto, Portugal, and also with REQUIMTE/LAQV, ISEP, Porto Polytechnic, 4249-015 Porto, Portugal.

B. Malheiro is with the School of Engineering, Porto Polytechnic, 4249-015 Porto, Portugal, and also with the Centre of Robotics and Autonomous Systems, INESC TEC, 4200-465 Porto, Portugal (e-mail: mbm@isep.ipp.pt).

E. Arnó and I. Perat are with the School of Engineering of Vilanova i la Geltrú, Polytechnic University of Catalonia, 08800 Vilanova i la Geltrú, Spain.

M. F. Silva is with the School of Engineering, Porto Polytechnic, 4249-015 Porto, Portugal, and also with the Centre of Robotics in Industry and Intelligent Systems, INESC TEC, 4200-465 Porto, Portugal.

P. Fuentes-Durá is with the School of Design Engineering, Universitat Politècnica de València, 46022 Valencia, Spain.

P. Guedes and P. Ferreira are with the School of Engineering, Porto Polytechnic, 4249-015 Porto, Portugal.

Digital Object Identifier 10.1109/TE.2019.2926944
Findings: Iberian EPS faculty and students are aware of the social, economic, and environmental impact of their projects, in terms of quality of life, social responsibility, the use of resources, and environmentally friendly technology.

Index Terms-Capstone project, diversity, engineering, European project semester, higher education, sustainability.

\section{INTRODUCTION}

$\mathbf{E}$ DUCATION for Sustainable Development empowers and motivates learners to become active sustainability citizens, capable of critical thinking and able to participate in shaping a sustainable future [1]. According to UNESCO, engineering is one of the most important activities in the context of sustainable development and, consequently, future engineers need to incorporate sustainability into their practice to improve the quality of life for all [2]. However, the engineering community lacks consensus on established methods for infusing sustainability into the curriculum and on verified approaches to assess engineers' sustainability knowledge [3]. Typically, engineering degrees address this challenge by explicitly including in the syllabus mandatory or optional modules on design, ethics, sustainability, or by implicitly using project-based learning cornerstone or capstone modules to convey these skills. In this context, engineering capstone projects can be essential tools to educate for sustainable development education, since they allow students to reach what Bielefeldt [4] terms the "synthesis level" and develop effective outcomes related to sustainability.

This paper reports that the engineering capstone programs run by Iberian European Project Semester (EPS) providers train engineering undergraduates to design ethical sustainable solutions. This is achieved through the design and application of a sustainability learning assessment method based on the analysis of program set-up (syllabi, project briefs and report templates) and student final reports. In this study, a sustainability-driven project: (i) uses resources in a way that neither compromises the environment nor depletes materials for future generations; (ii) improves the quality of life for all; (iii) reveals social and environmental responsibility; and (iv) adopts environmentally-friendly technologies. A sustainability project is not only driven by sustainability, but contributes 
to the achievement of the United Nations (UN) Sustainable Development Goals (SDG).

This paper is organized as follows: Section II provides a review of: (i) the UNESCO, European Network for Accreditation of Engineering Education (ENAEE), ABET and NAE recommendations on engineering education for sustainable development; (ii) sustainability in engineering capstone programs; and (iii) sustainability learning assessment in engineering; Section III presents the EPS framework and the EPS implementations in Portugal and Spain; Section IV describes the method used in this work; Section V presents the results, discussed in Section VI; and Section VII draws conclusions.

\section{BACKGROUND}

\section{A. Engineering Education for Sustainable Development}

Engineering, through its role in the creation and implementation of technology, has been a major driver of economies, health and quality of life. Poorly-designed engineering systems have negative impacts such as pollution, global warming, depletion of scarce resources, and catastrophic failures. To foster the necessary expertise in future engineers, several organizations have pointed to the need to address aspects of sustainability in higher education engineering courses:

- UNESCO says engineers must increasingly be aware of social and environmental impacts of technology, and work in complex teams, interacting and cooperating with society [2], to effectively contribute to achievement of Sustainable Development Goals (SDG). ${ }^{1}$

- ENAEE states that the learning process should enable engineering graduates to demonstrate, among other competences, knowledge and understanding of societal, health and safety, environmental, economic and industrial implications, as well as critical awareness of economic, organizational and managerial issues of the engineering practice [5].

- ABET, in their Engineering Criteria 2000 (EC2000) [6], says students should attain an understanding of professional and ethical responsibility, and have the broad education necessary to understand the impact of technical solutions in a global, economic, environmental and societal context.

- NAE [7] advocates engineering practices that incorporate attention to sustainable technology. They state that engineers must be educated to consider issues of sustainability in all aspects of design and manufacturing. Of the 14 grand challenges faced by engineering, NAE state that five match directly to SDG.

Table I summarizes the key skills required in future engineers, according to the surveyed organizations. Sustainable engineering requires an interdisciplinary approach with all engineering fields incorporating sustainability into their practice to improve the quality of life for all [8].

\footnotetext{
${ }^{1}$ https://www.un.org/sustainabledevelopment
}

TABLE I

FUTURE ENGINEER SKILLS

\begin{tabular}{|c|c|c|c|c|c|c|c|c|c|c|}
\hline Organization & 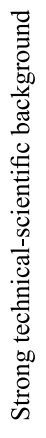 & 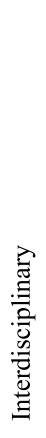 & 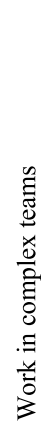 & 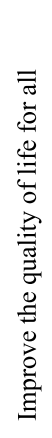 & 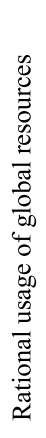 & 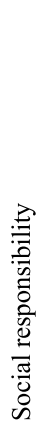 & 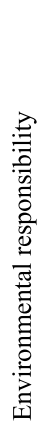 & 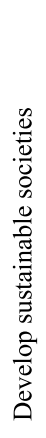 & 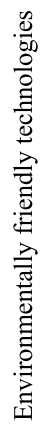 & 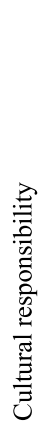 \\
\hline UNESCO [8] & $\checkmark$ & $\checkmark$ & $\checkmark$ & $\checkmark$ & $\checkmark$ & $\checkmark$ & $\checkmark$ & $\checkmark$ & $\checkmark$ & \\
\hline ENAEE [5] & $\checkmark$ & $\checkmark$ & $\checkmark$ & $\checkmark$ & & $\checkmark$ & $\checkmark$ & $\checkmark$ & & $\checkmark$ \\
\hline ABET [6], [9] & $\checkmark$ & & & & & $\checkmark$ & $\checkmark$ & $\checkmark$ & $\checkmark$ & $\checkmark$ \\
\hline NAE [7] & $\checkmark$ & & & $\checkmark$ & $\checkmark$ & $\checkmark$ & $\checkmark$ & $\checkmark$ & $\checkmark$ & $\checkmark$ \\
\hline
\end{tabular}

\section{B. Sustainability in Engineering Capstone Projects}

Engineering capstone projects combine project-based and active learning methods with teamwork and soft skills development to prepare undergraduates to face the challenges of their future professional lives. Although capstone programs are ideal vehicles to educate for sustainable development, the literature review performed found few capstone programs that, like EPS, have this goal.

Oladiran et al. present the Global Engineering Teams program where students from Germany and South Africa, Botswana, Brazil and Chile work in collaboration with industry partners on projects [10]. The teams need to consider "engineering tasks holistically to promote global sustainability in terms of economic, ecological and socio-political principles". However, the authors fail to explain how they assess sustainability learning.

Stanford et al. describe a capstone program for civil engineering undergraduates [11]. The authors employ a combination of qualitative and quantitative assessment tools, including surveys, journals, interviews, and timecards to investigate how students acquire sustainability-related values. Results not only revealed that real-world projects with a focus on sustainability have a positive impact on students' critical thinking skills and knowledge of sustainability, but also suggested that open-ended problems with real constraints yield a uniquely beneficial learning experience without sacrificing the quality of student design or project deliverables.

Dancz et al. report the development and application of a sustainability rubric to civil engineering senior design capstone projects [3]. The rubric considers: (i) Bloom's knowledge, comprehension, application, analysis, synthesis, and evaluation cognitive levels; (ii) the number of times the economic, environmental, and social pillars of sustainability were discussed in student reports; (iii) the connections and inter-relatedness between the three dimensions of sustainability; and (iv) the motivations, quantitative/qualitative incorporation of sustainability and references. Rubric evaluation of student reports revealed that students' performance in senior design projects is primarily driven by their instructors' expectations. When guided by a project mentor and/or a client with a sustainability 
mission, students demonstrated ability to apply sustainability successfully to their senior design projects.

Palacin-Silva et al. describe a capstone team-oriented project for software engineering undergraduates focused on software services for sustainability [12]. The course follows a collaborative learning approach, where students worked together to engineer a software project, with the lecturer as a facilitator. The projects' challenge is to link information and communication technologies to greening solutions, incorporating social, economic and environmental concerns by involving computing, environmental sustainability and citizen engagement. The method used identifies the sustainability requirements and verifies how they are met by the device applications [12].

\section{Sustainability Learning Assessment}

When considering sustainability learning assessment, researchers conduct student surveys (at the start and end of the program) [11], ask students to create concept maps (start and end of the program) and analyze their content with word clouds [13], apply existing assessment frameworks, like the Sustainability in Higher Education Assessment Rubric [14] or the Social, Economic, Ecological, Technological and Time framework [15], create assessment rubrics [4], [11], or combine existing methods [3].

Concept (or cognitive) maps have been used to assess how well students have learned sustainability concepts and their relationships [16]. Concept maps have the benefit of providing a consistent assessment metric for longitudinal learning of sustainability concepts [17].

Word clouds are a Big Data visualization technique that highlights the most frequent relevant words present in a text [18]. This visual representation of textual data provides a creative way to communicate qualitative data [19]. In the context of sustainability assessment, word clouds allow visual and thematic analysis of the depth and breadth of student sustainability knowledge [13].

The Sustainability in Higher Education Assessment Rubric is a course outcome-based rubric based on these key elements: (i) knowledge and awareness; (ii) skills development; (iii) responsibility; (iv) lifelong learning; (v) application in diverse settings; (vi) diverse interaction; (vii) reflection; and (viii) partnerships with communities or institutions. The Social, Economic, Ecological, Technological and Time assessment framework defines social, economic, ecological, technological and time assessment criteria to establish: (i) the relative dependence of the economy on nonrenewable sources of energy and materials; (ii) the productivity of energy and materials consumed; and (iii) the dissipative loss, especially of toxic and hazardous substances [15].

\section{European Project Semester}

The European Project Semester (EPS) is a onesemester engineering capstone program, designed by Arvid Andersen [20], that implements student-centered project-based learning. Its goal is to expose participants from diverse cultures and scientific backgrounds to teamwork and multidisciplinary problem-solving [21]. Currently, it is offered by 19 European higher education institutions, called EPS providers, in 12 different countries. ${ }^{2}$

\section{A. EPS Framework}

The EPS defines of a common syllabus, consisting of a project and accompanying intensive modules, designed to prepare students for collaboration in an international setting. EPS providers implement the program in accordance with the "10 Golden Rules of EPS" 3 that state: English is the working language; an EPS is worth 30 European Credit Transfer System Units (ECTU), with a minimum of 20 ECTU for the project and five ECTU to ten ECTU for the accompanying modules; foreign language, team building and project management are mandatory accompanying modules; and teams must include students from different countries and scientific backgrounds [22]. Despite this common structure, each institution still enjoys some degree of freedom in their implementation of EPS. The program is addressed mainly (but not exclusively) to incoming exchange students, so that the class becomes a truly international setting. A project is assigned to each team of four to six students, who have different nationalities and fields of study (engineering, product design and business programs).

Over the program's 15 weeks the teams participate in scheduled project and project support activities. In weekly project meetings, project advisers act as coaches, rather than supervisors, to promote students' autonomy and responsibility. The teams make their design and development decisions, and justify them, based on requirements, studies and experiments. The two main milestones are: (i) the mid-semester interim presentation and discussion, where teams and team members get feedback from peers, module teachers and project advisers; and (ii) the end of semester final presentation, discussion and assessment, where teams and team members are evaluated based on self- and peer-assessment, and contributions from teachers and advisers.

\section{B. EPS in Iberia}

In the Iberian Peninsula, EPS is offered in Portugal by the Instituto Superior de Engenharia do Porto (ISEP), the School of Engineering of the Porto Polytechnic, and in Spain by the School of Engineering of Vilanova i la Geltrú of the Polytechnic University of Catalonia (UPC) and the School of Design Engineering of the Universitat Politècnica de València (UPV). EPS has been offered at UPV since 2005, at UPC since 2008, and at ISEP since 2011. Their syllabi have in common the project module (worth at least 20 ECTU), sustainability, project management and team building support modules, and a foreign language module. All project support modules are intensive (from 12 to 36 contact hours) and focused, frequently taking the form of seminars or workshops. Iberian EPS providers favor not only offering project themes with a strong sustainability component, but systematically addressing sustainability education through dedicated

\footnotetext{
${ }^{2}$ http://www.europeanprojectsemester.eu

${ }^{3}$ http://www.europeanprojectsemester.eu/concept
} 
modules and mandatory content in team deliverables (see next section).

The EPS at ISEP involves faculty from eight departments and has a multidisciplinary panel of project advisers, instead of individual project advisers. It offers two modules where sustainability is explicitly addressed: "Energy and Sustainable Development" and "Ethics and Deontology". The report template has eight chapters, including the "Eco-Efficiency Measures for Sustainability" and "Ethical and Deontological Concerns", where teams consider the social, economic and environmental ethics concerns associated with their project. The teams are expected to design solutions based on the state of the art, ethical and sustainability concerns and marketing studies, and to procure and purchase materials from local providers to implement and test a proof-of-concept prototype. For deliverables, each team maintains a project wiki and produces a report (interim and final), a technical-scientific paper, a poster, a leaflet, a brochure and a video.

UPC offers multidisciplinary projects that focus on environmentally-oriented problems, in collaboration with companies, public institutions and research groups. The EPS provides an excellent international setting to illustrate the different approaches that distinct countries take to environmental problems [23]. The EPS at UPC was complemented in 2011 by the International Design Project Semester (IDPS), a spin-off program that followed the same rules as the EPS, but that focused on ecological and sustainable industrial design as the main thrust of the projects. The IDPS specifically refers to an underlying sustainability perspective and to an emphasis on sustainable design: (i) developing "their projects from a sustainability perspective"; and (ii) "IDPS projects need to be design-focused with particular emphasis on sustainability" [23]. This emphasis on sustainability is reflected in the EPS and IDPS structures, both of which have at least one course or module devoted to sustainability.

At UPV, EPS involves faculty from nine different departments and several companies, including multinationals and start-ups. UPV welcomes exchange students (mainly undergraduates), offering new opportunities with added value. EPS at UPV is an effective ecosystem of support for students and faculty. At UPV, the main learning method practiced by students, faculty and clients is self-reflection. It involves team brainstorming (over the project and case studies) and aims to explore fresh perspectives.

To ensure the continuous improvement of future offerings of the course, satisfaction surveys are distributed to the students at the end of the semester and open innovation surveys are shared within the EPS network to disseminate news and ideas, establish collaborations and explore trends.

\section{METHOD}

This study investigated the extent to which environmental concerns are addressed across the three EPS programs in the Iberian Peninsula. The approach was data holistic, examining all program components for each of the three EPS providers, including syllabi, project briefs and reports (19 at ISEP, 37 at UPC and 34 at UPV), for a five-year period

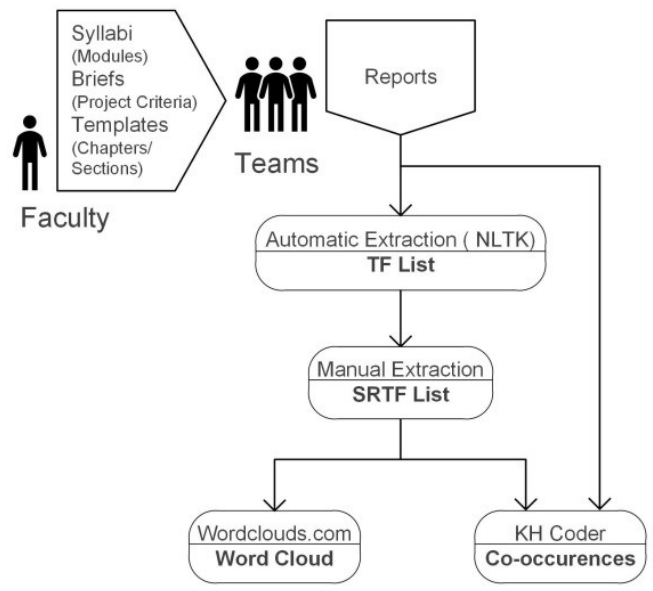

Fig. 1. Method for assessing sustainability in EPS.

(2011-2015), collected from their institutional archives and websites. Evidence for sustainability was explored at three levels: syllabus (support modules), project briefs and final reports, including the full text and dedicated chapters or sections. The syllabi, project briefs and report templates reflect faculty views on sustainability, while the project reports reflect student views. Fig. 1 illustrates the assessment method adopted.

An evidence-based analysis was applied to faculty material, and a semi-automatic analysis to student reports. The semi-automatic analysis includes: (i) pre-processing reports to remove student names, numbers, captions, template headings and irrelevant sections (acknowledgments and references); (ii) automatic generation of the term-frequency (TF) list for the reports with a natural language tool kit (NLTK); (iii) manual identification of the sustainability-related termfrequency (SRTF) list; (iv) creation of the report word clouds from the SRTF lists using WordClouds.com ${ }^{4}$; and (v) generation of the co-occurrence network between the TF list of the chapter parts and the SRTF list using KH Coder. ${ }^{5}$

The framework used for analyzing evidence of sustainability was the United Nations resolution on Transforming Our World: the 2030 Agenda for Sustainable Development [24]. In particular, a sustainability problem meets both the problem nature and requirements criteria, and a sustainability-driven project meets the requirements criteria. The search for sustainability-related terms identifies which concepts appeared in the reports and the criteria they referred to (use of resources, quality of life, environmentally friendly technology, and social and environmental responsibility).

Project briefs, which can be submitted by companies or academia, are reviewed by EPS faculty to ensure that they are open-ended, multidisciplinary and sustainability-driven. These briefs allowed identification of projects addressing sustainability problems.

Project reports were analyzed for the presence of parts (chapters, sections or appendices) dedicated to sustainability. In addition, given the broad scope of sustainable development,

\footnotetext{
${ }^{4}$ https://www.wordclouds.com/

${ }^{5}$ http://khcoder.net/en/
} 
TABLE II

EPS - Sustainability EVIDENCE SOURCES OF ISEP, UPC AND UPV (2011-2015)

\begin{tabular}{lll}
\hline Program Syllabus & Document & Evidence \\
\hline \multirow{2}{*}{ Project module } & Brief & Sustainability project \\
& Report & Part(s) devoted to sustainability \\
Report & $\begin{array}{l}\text { Sustainability-related terms } \\
\text { Sodule(s) devoted to } \\
\text { sustainability }\end{array}$ \\
\hline
\end{tabular}

note was taken of how students understood the concept of sustainability and presented this in their project reports. This analysis is presented in the form of word clouds, allowing a simple and intuitive interpretation of the most salient terms related to sustainability. Table II summarizes the sources of evidence used in the three programs.

The reports were pre-processed to remove student data, template headings, numbers, captions and irrelevant sections (acknowledgements and references), then submitted to Python NLTK for the automatic removal of stop words, lemmatization and term-frequency analysis. The list of stop words used included the long list from Ranks NL. ${ }^{6}$ Next, the termfrequency (TF) list was manually filtered for sustainabilityrelated terms associated with the requirements criteria. For this reason, the search for the noun "sustainability" (or the adjective "sustainable") also included adjacent concepts associated with economic, environmental and social sustainability, environment, resources and people; this produced the sustainability-related term-frequency (SRTF) list. The aim was to identify the views of sustainability underlying each report. The overall view of sustainability that emerged is captured in the corresponding word clouds. The SRTF lists were then submitted to WordClouds.com to generate the aggregated report word clouds. Finally, KH Coder, a free tool for quantitative content analysis, was used to determine if sustainability was present throughout the reports or just in certain sections of the reports. This analysis was performed with the 19 reports from ISEP because the same report template was used in this five-year period. The pre-processed reports were merged into a single text file and imported into a data sheet. Each paragraph was associated to the corresponding chapter in the data sheet file. Next, project-specific chapters (Introduction, State of the Art, Project Management, Project Development and Conclusions) were aggregated under EPS Project, resulting in four distinct report parts: Marketing Plan, Eco-efficiency Measures for Sustainability, Ethical and Deontological Concerns and EPS Project. The resulting textmined data and the SRTF list were submitted to KH Coder. To generate the co-occurrence network between SRTF and chapter parts, KH Coder was configured to use the top 60 SRTF words and the Jaccard distance. Again, the list of stop words includes the long list from Ranks NL.

\section{REsults}

The results document the findings collected from the syllabus, the project briefs and the corresponding team reports of

\footnotetext{
${ }^{6} \mathrm{https}: / /$ www.ranks.nl/stopwords
}

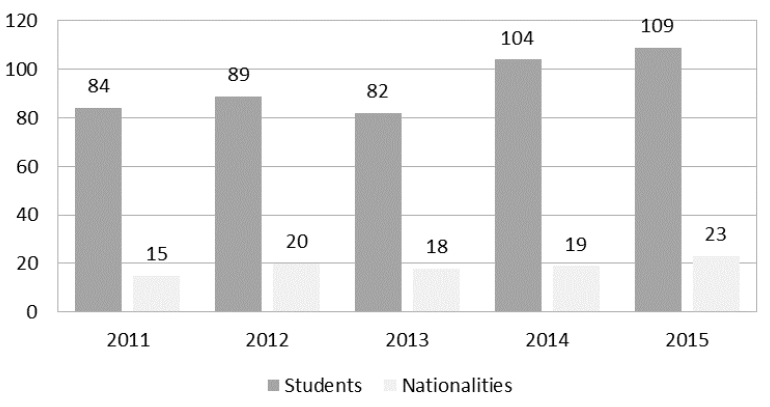

Fig. 2. Evolution of EPS students in Iberia (2011-2015).

the three EPS programs. Fig. 2 provides an overview of the number of students in Iberian EPS in the period of study, with an average of 94 students per year and five students per team.

\section{A. Syllabi}

The three syllabi differ only on two project support modules. While ISEP offers "Ethics \& Deontology" and "Energy and Sustainable Development", UPC provides "Systematic Innovation" and "Human Centered Design", and UPV "Systematic Innovation" and "Engineering Product Design". To avoid repetition, the framework of EPS is described using ISEP as an example and including some singularities from the other two providers. The EPS program provided by ISEP includes the project (20 ECTU) and five project support seminars (2 ECTU each) oriented towards the specificities of each team's project [25]-[27]:

- Project Management and Team Work (36 h): focuses on team building, task identification, human resource allocation, task planning and scheduling, resource management, plan enforcing and eventual rescheduling.

- Marketing and Communication (24 h): tackles the market analysis, segmentation and positioning of the prototype, and includes scientific-technical English, contributes to the development of the project deliverables.

- Energy and Sustainable Development (24 h): addresses the ecological footprint and life-cycle analysis.

- Ethics and Deontology (12 h): analyzes the engineering, sales and marketing, academic and environmental ethics.

- Foreign Language (42 h): covers local culture and language.

At UPC the emphasis on sustainability is reflected in the syllabi of the EPS and IDPS, which contain at least one module devoted to sustainability. Table III shows the intensive sustainability modules of EPS (and IDPS) at UPC, over the period 2011-2015.

At UPV the sustainability seminar is different every year, depending on the nature of the ongoing projects. Often an introduction to eco-design, it can sometimes be more related to renewable energies, environmental technologies or business sustainability.

\section{B. Project Briefs}

EPS project briefs are intentionally short and open-ended. They give the project title, a few sentences describing the 
TABLE III

UPC - Sustainability Modules OfFEREd AS PART OF EPS (2011-2015)

\begin{tabular}{lcccccc}
\hline Support Module & ECTU & 2011 & 2012 & 2013 & 2014 & 2015 \\
\hline $\begin{array}{l}\text { Sustainability and } \\
\text { Business }\end{array}$ & 1 & $\checkmark$ & $\checkmark$ & & & \\
Sustainable Engineering & 1 & & & $\checkmark$ & $\checkmark$ & \\
Eco-Design & 3 or 1 & & $\checkmark$ & & & $\checkmark$ \\
Social Sustainable Design & 1 & & & $\checkmark$ & $\checkmark$ \\
Sustainable Value Design & 3 & $\checkmark$ & & \\
\hline \multicolumn{4}{l}{ *ECTU value varied by year }
\end{tabular}

problem and a set of broad requirements, such as the budget, applicable European directives, mandatory adoption of the International System of Units, open source software and lowcost hardware. ${ }^{7}$ The project briefs chosen by EPS teams in the three Iberian institutions were analyzed to identify those specifically addressing sustainability problems; this identification was based on the key concepts of a sustainability project, as mentioned above.

ISEP typically proposes multidisciplinary problems related to sustainability [28], bio-mimetic robotics [22], environmental technology [29], [30] and sustainable food production [29], [31], [32]. In the period of study, nine out of a total of 19 projects were dedicated to solving sustainability challenges, ranging from the monitoring of the level of waste oil tanks, solar dryers, aquaponic systems, re-configurable LED lamps or insect farming.

At UPC in this period half of the projects addressed various types of sustainability problems, ranging from energy consumption and production, to social and equity issues, the environment, ecology or the life cycle of products.

At UPV, the most common project areas are robotics, innovation for leisure and urban design. A total of 16 projects were dedicated to solving sustainability problems, ranging from the design of sustainable products (furniture, tiles, vending machines), the preservation of natural resources (fauna, coastline), to engineering solutions, while being cognizant of people's aspirations and cultures (urban spaces, safety, theatre, inclusion).

During this five-year period, 43 of a total of 90 teams (48\%) worked on sustainability problems. Table IV lists a sampling of these projects, grouped by UN SDG. Additional information on some of these projects can be found in [31], [33]-[37].

\section{Report Structure}

Students' final reports were examined to see if they included a specific chapter, section or appendix devoted to sustainability. The majority (81 \%) did, having an entire chapter, section or appendix on sustainability with titles such as Sustainability Report, Eco Audit Report, Eco-efficiency Measures for Sustainability or Ethical and Deontological Concerns. For example, the ISEP report template has eight

${ }^{7} \mathrm{~A}$ sample project brief is available at https://www.dropbox.com/ s/ubd0seoitgwilf9/EPS_PROJECT_2015_Insectarium_P04.pdf.
TABLE IV

Sample Projects Grouped by UN Sustainable DEVELOPMENT GOALS (2011-2015)

\begin{tabular}{ll}
\hline Sustainable Development Goal & Project \\
\hline 2. Zero hunger & $\begin{array}{l}\text { Insectarium (ISEP), Solar dehydrator } \\
\text { (ISEP), Aquaponics (ISEP) } \\
\text { Water desalinator (UPC), Fluid } \\
\text { disinfection (ISEP) }\end{array}$ \\
7. Affoan water and sanitation & Reconfigurable LED lamp (ISEP) \\
& $\begin{array}{l}\text { Urban node (UPC), Accessibility and } \\
\text { universal design (UPC, UPV), Eco- } \\
\text { vending machines (UPV), School bus }\end{array}$ \\
11. Sustainable and communities & $\begin{array}{l}\text { Driver alert (UPV), Smart structures } \\
\text { cities }\end{array}$ \\
(UPC) \\
13. Climate action & Environmental education (UPV) \\
14. Life below water & Marine buoy (UPC, ISEP) \\
15. Life on land & Wildlife crossing (UPV) \\
\hline
\end{tabular}

chapters; four address topics covered in support modules (Project Management, Marketing Plan, Eco-efficiency Measures for Sustainability and Ethical and Deontological Concerns) and the remaining chapters are project related (Introduction, State of the Art, Project Development and Conclusions).

\section{Report Word Clouds}

The last step was to filter the reports to collect sustainabilityrelated terms. The word cloud generated from ISEP's reports, Fig. 3, shows that the teams were clearly aware of the need to adopt environmentally friendly technologies, and rational and sustainable use of resources.

The most frequent terms indicate concerns about the environment (water, material, energy / power / battery, environment / environmental, temperature, solar, wind, air), sustainability (sustainable / sustainability), ethics (ethic / ethical) and, to a lesser extent, with the social (social, safety, life/human) and economic (budget) dimensions.

The UPC word cloud, Fig. 4, depicts sustainability as a wide-ranging concept related to a variety of areas. The most common concepts include sustainable energy, sustainable materials, sustainable solution, or sustainable development. Some less common, but interesting, concepts that emerge from some of the projects include lightweight, habits, hightech, or elegant, thus linking sustainability (or sustainable) to fashionable lifestyles or marketing.

The UPV word cloud, Fig. 5, shows that sustainability is a complex concept related to people's needs, product design and awareness of the future of the environment. Basic terms, like energy, materials and water, are mixed with others from specific projects (furniture, theatre, robot, tiles, and children).

\section{E. Sustainability Co-Occurrence in Chapters}

To understand if sustainability is a pervasive, underlying concern in the reports, or simply a concept addressed in specific areas when required, ISEP reports were analyzed with KH Coder. ISEP data was selected because their report template was constant over this five-year period. For the processed report chapters, Fig. 6 shows the set of sustainability related terms, their relative frequency and inter-relatedness. Three 


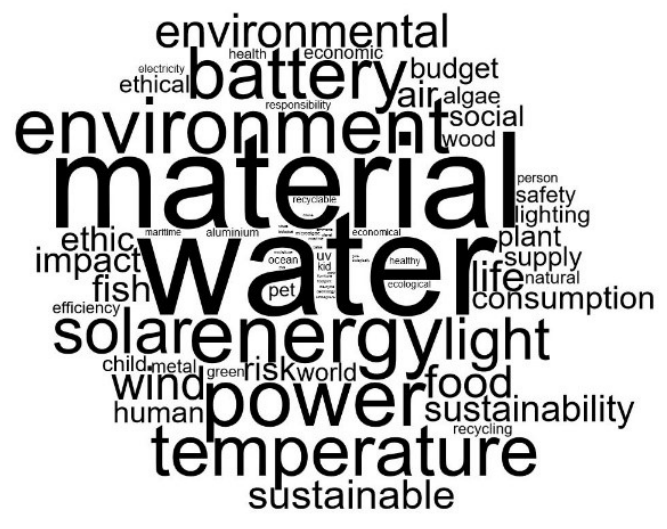

Fig. 3. ISEP's sustainability word cloud (2011-2015).

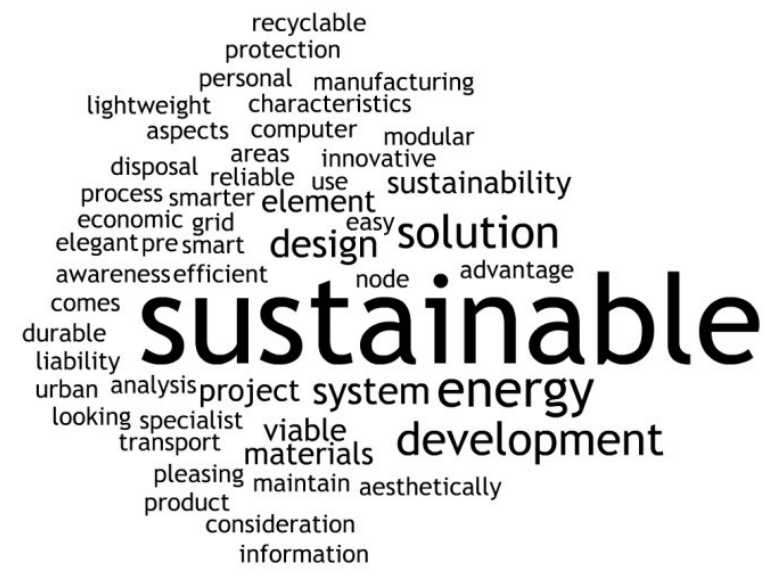

Fig. 4. UPC's sustainability word cloud (2011-2015).

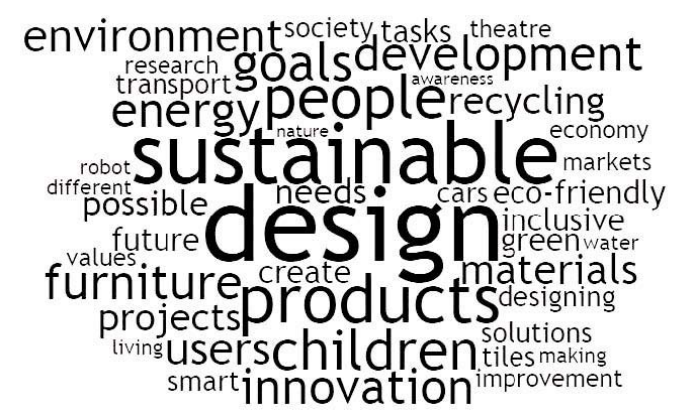

Fig. 5. UPV's sustainability word cloud (2011-2015).

squares represent the Marketing Plan, Eco-efficiency Measures for Sustainability, Ethical and Deontological Concerns chapters. The fourth square, EPS Project, aggregates data for the project-specific chapters (Introduction, State of the Art, Project Management, Project Development, and Conclusions). Circles represent the sustainability-related terms; their diameter is proportional to the relative frequency of each term and links indicate the relationship between terms and chapters. The network shows that sustainability is, in fact, pervasive throughout the analyzed reports. EPS Project shares multiple sustainabilityrelated terms with Eco-efficiency Measures for Sustainability

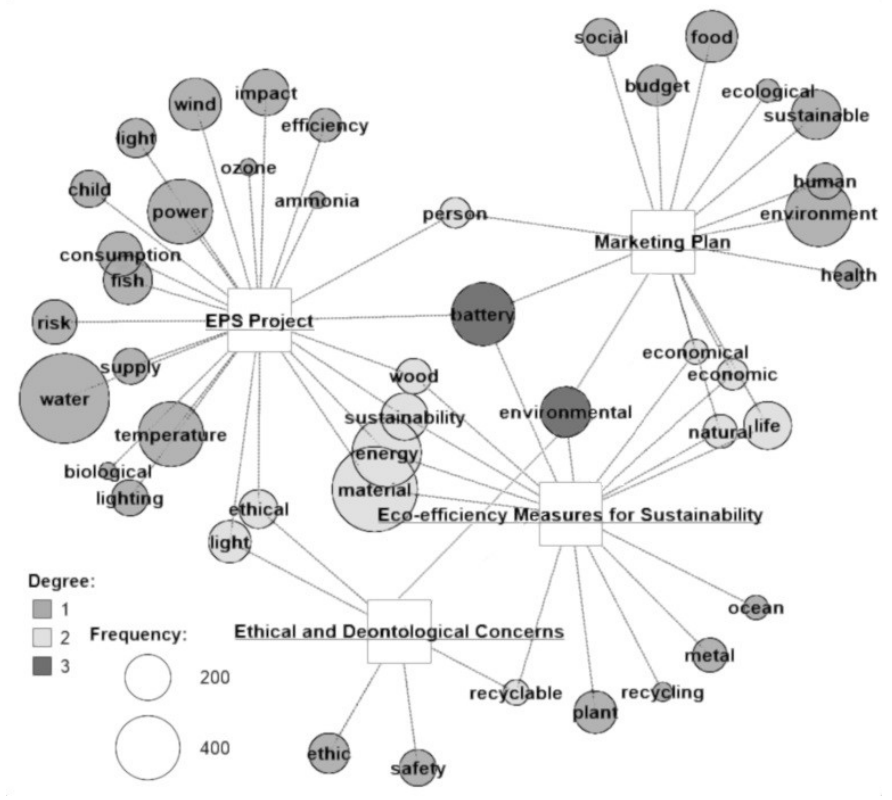

Fig. 6. ISEP's sustainability co-occurrence chapter network (2011-2015).

chapter and fewer with Ethical and Deontological Concerns and Marketing Plan.

\section{DISCUSSION}

The following analysis of the Iberian EPS programs provides the faculty and student views on sustainability.

\section{A. Method}

The sustainability learning assessment method used analyzed the program (modules, briefs and templates) and student reports. The programs were filtered for evidence of sustainability concerns, and reports were processed with text processing tools to collect and visualize the presence of sustainabilityrelated terms through word clouds, and to show their relationship with report sections with $\mathrm{KH}$ Coder. Other works have used concept maps [13], [16], word clouds [13], assessment rubrics [4], [11], [14], [15], and questionnaires, interviews and timecards [11] to assess students' learning of sustainability concepts and their relationships. In distinction to these previous works, dependent on some type of dedicated data collection process, the method used here draws its data exclusively from faculty input (program syllabi, project briefs and report template) and team output (reports). It performs an evidence-based analysis of faculty inputs and a semi-automatic analysis of the team reports, using generic data mining tools, to validate the original claim. The sole manual step in the report analysis is identifying the list of sustainability-related terms. This current method is thus sufficiently general for wide range application.

\section{B. Faculty Perspective}

From their syllabi, the three providers shared the central project module, the foreign language module and the sustainability, project management and team building support 
modules. These provided a strong common basis for the joint analysis of the three EPS programs and their outcomes in terms of sustainability.

From the project briefs, over the five-year period, 43 of a total of 90 teams $(48 \%)$ worked on sustainability problems. This figure only considers sustainability-driven projects that address sustainability problems, indicating the relevance faculty gives to sustainability.

The analysis of the reports showed that not only did the majority $(81 \%)$ include an entire chapter, section or appendix on sustainability, indicating that this was a major faculty concern, but their contents included multiple sustainability-related terms. The gathered data set was then used to generate termfrequency word clouds and the chapter term co-occurrence network.

The faculty's strong perspective on sustainability is embedded in the program through the dedicated support modules offered, the nature of the problems posed and the structure of report templates. That, according to Dancz et al. [3], is a recommended approach for having students successfully apply sustainability in their senior design projects, since they are primarily driven by their instructor's expectations. Moreover, according to Stanford et al. [11], the characteristics of EPS projects-open-ended problems with real project constraints-contribute to a positive impact on students' critical thinking skills and sustainability knowledge.

\section{Student Perspective}

The three word clouds, Figs. 3 to 5, illustrate the central role of sustainability in Iberian EPS projects. As well as being involved in goals, tasks and solutions, it is the focus of a wide range of the problems covered. The most encouraging finding is that the students at all three institutions displayed concern about the environmental impact, social implications and economic viability of engineering solutions. The generated word clouds show a focus on quality of life and social responsibility (UPV), on use of resources (ISEP, UPC and UPV) and on environmentally friendly technology (ISEP and UPC). Sustainability therefore emerges as a wide-ranging concept that applies to development, materials, energy or design - not surprising, given the all-encompassing definition adopted in this study. The word cloud visual and its thematic analysis have previously been used to display the depth and breadth of student sustainability knowledge, for example by Barella et al. who created word clouds to compare sustainability-related concept maps drawn by the students at the start and end of a program [13]. Similarly, here the word clouds display the student perspective on sustainability.

The co-occurrence analysis of the chapter sustainabilityrelated terms provided an important insight: within ISEP's reports, sustainability is a pervasive concern because it is not confined to dedicated chapters, sections or appendices. This is a major finding since it indicates students were able to incorporate sustainability into their practice (project design and development).
Overall, the results provide considerable evidence to substantiate the three providers' claim that their EPS capstone programs educate participants for sustainable development.

\section{CONCLUSION}

The idea of sustainability must be anchored in analysis of social implications, economic viability and environmental impact; emphasis can shift between these dimensions. Engineers must be aware of the need to balance these complex and interdependent dimensions when designing new technical solutions. In EPS, future engineers work in multicultural and multidisciplinary teams to design solutions, develop and test proofs of concept, seeking to contribute to a better world.

This paper details a method, based on analysis of program syllabi, project briefs, project templates and final reports, to assess sustainability learning within engineering capstone programs and applies this to the three Iberian EPS programs.

The results suggest that Iberian EPS programs are oriented towards sustainability, as shown by the inclusion of specific modules to promote sustainable awareness, the selection of sustainability problems and the adoption of a sustainabilitydriven design methodology. The programs empower students with a vision of socially responsible action, enabling them to become agents of sustainable development. Based on these results, the adoption of the EPS framework is recommended for other higher education institutions training engineers in the practice and awareness of sustainability (where necessary adapting to local constraints such as legislation). The program provides a rich learning environment, with studentdirected projects, posing complex and authentic challenges, carried out in interdependent multidisciplinary collaboration. Engineering educators become coaches, rather than teachers, assisting the international multidisciplinary student teams in designing sustainable and ethical solutions for the benefit of society.

\section{ACKNOWLEDGMENT}

The authors would like to thank their home institutions and Prof. J. Hansen, as well as the network of EPS providers, for the support and contribution given to the implementation of EPS in the Iberian Peninsula.

\section{REFERENCES}

[1] M. Rieckmann, Education for Sustainable Development Goals: Learning Objectives, UNESCO, Paris, France, 2017.

[2] "Engineering: Issues, challenges and opportunities for development," United Nat. Educ. Sci. Cult. Org., Paris, France, Rep., 2010. Accessed: Jun. 2019. [Online]. Available: http://unesdoc. unesco.org/images/0018/001897/189753e.pdf

[3] C. L. A. Dancz et al., "Utilizing civil engineering senior design capstone projects to evaluate students' sustainability education across engineering curriculum," Adv. Eng. Educ., vol. 6, no. 2, pp. 1-27, 2017.

[4] A. R. Bielefeldt, "Pedagogies to achieve sustainability learning outcomes in civil and environmental engineering students," Sustainability, vol. 5, no. 10 , pp. 4479-4501, 2013.

[5] European Network for Accreditation of Engineering Education. (2015). EUR-ACE Framework Standards and Guidelines (EAFSG). Accessed: Jun. 2019. [Online]. Available: https://www.enaee.eu/wpassets-enaee/uploads/2012/02/EAFSG_full_nov_voruebergehend.pdf 
[6] Accreditation Board for Engineering and Technology. (2006). Engineering Change: A Study of the Impact of EC2000. Accessed: Jun. 2019. [Online]. Available: http://www.abet.org/wpcontent/uploads/2015/04/EngineeringChange-executive-summary.pdf

[7] National Academy of Engineering, The Engineer of 2020: Visions of Engineering in the New Century. Washington, DC, USA: Nat. Acad. Press, 2004.

[8] UNESCO. (2015). Sustainable Engineering. Accessed: Jun. 2019. [Online]. Available: http://www.unesco.org/new/en/naturalsciences/science-technology/engineering/sustainable-engineering/

[9] Accreditation Board for Engineering and Technology. (2008). Going Global Accreditation Takes Off Worldwide-2008 Annual Report for ABET Fiscal Year 2007-2008. Accessed: Jun. 2019. [Online]. Available: http://www.abet.org/wp-content/uploads/2015/04/2008-ABET-AnnualReport-.pdf

[10] M. T. Oladiran, J. Uziak, M. Eisenberg, and C. Scheffer, "Global engineering teams-A programme promoting teamwork in engineering design and manufacturing," Eur. J. Eng. Educ., vol. 36, no. 2, pp. 173-186, 2011.

[11] M. S. Stanford et al., "Evaluating student and faculty outcomes for a real-world capstone project with sustainability considerations," J. Prof. Issues Eng. Educ. Pract., vol. 139, no. 2, 2013, Art. no. 123133.

[12] M. V. Palacin-Silva, A. Seffah, and J. Porras, "Infusing sustainability into software engineering education: Lessons learned from capstone projects," J. Clean. Prod., vol. 172, pp. 4338-4347, Jan. 2018.

[13] E. M. Barrella and M. K. Watson, Comparing the Outcomes of Horizontal and Vertical Integration of Sustainability Content Into Engineering Curricula Using Concept Maps. Cham, Switzerland: Springer Int., 2016, pp. 1-13.

[14] D. R. Riley, A. V. Grommes, and C. E. Thatcher, "Teaching sustainability in building design and engineering," J. Green Build., vol. 2, no. 1, pp. $175-195,2007$.

[15] A. M. Hasna, "Embedding sustainability in capstone engineering design projects," in Proc. IEEE EDUCON Conf., Apr. 2010, pp. 1601-1610.

[16] J. Segalàs, D. Ferrer-Balas, and K. F. Mulder, "Conceptual maps: Measuring learning processes of engineering students concerning sustainable development," Eur. J. Eng. Educ., vol. 33, no. 3, pp. 297-306, 2008.

[17] R. L. Nagel, E. C. Pappas, and O. Pierrakos, "On a vision to educating students in sustainability and design-The James Madison University School of Engineering approach," Sustainability, vol. 4, no. 1, pp. 72-91, 2012.

[18] F. Leal, J. M. Dias, B. Malheiro, and J. C. Burguillo, "Analysis and visualisation of crowd-sourced tourism data," in Proc. 9th Int. C* Conf. Comput. Sci. Softw. Eng. (C3S2E), Porto, Portugal, 2016, pp. 98-101.

[19] S. Graham, I. Milligan, and S. Weingart, Exploring Big Historical Data: The Historian's Macroscope. London, U.K.: Imperial College Press, 2015.

[20] A. Andersen, "Implementation of engineering product design using international student teamwork-To comply with future needs," Eur. J. Eng. Educ., vol. 26, no. 2, pp. 179-186, 2001.

[21] A. Andersen, "Preparing engineering students to work in a global environment to co-operate, to communicate and to compete," Eur. J. Eng. Educ., vol. 29, no. 4, pp. 549-558, 2004.

[22] M. F. Silva et al., "Development of biomimetic robots in the EPS engineering programme capstone project," in Proc. 3rd Int. Conf. Technol. Ecosyst. Enhanc. Multicult. (TEEM), Porto, Portugal, 2015, pp. 227-234.

[23] Escola Politècnica Superior d'Enginyeria de Vilanova i la Geltrú. (2018) European Project Semester. Accessed: Jun. 2019. [Online]. Available: http://www.epsevg.upc.edu/eps

[24] United Nations General Assembly. (2015). Transforming Our World: The 2030 Agenda for Sustainable Development. Accessed: Jun. 2019. [Online]. Available: https://sustainabledevelopment. un.org/post2015/transformingourworld

[25] B. Malheiro, M. Silva, M. C. Ribeiro, P. Guedes, and P. Ferreira, "The European project semester at ISEP learning to learn engineering," in Proc. 1st Int. Conf. Portuguese Soc. Eng. Educ. (CISPEE), Oct. 2013, pp. 1-8.

[26] B. Malheiro, M. Silva, M. C. Ribeiro, P. Guedes, and P. Ferreira, "The European project semester at ISEP: The challenge of educating global engineers," Eur. J. Eng. Educ., vol. 40, no. 3, pp. 328-346, 2015.

[27] B. Malheiro, M. Silva, P. Ferreira, and P. Guedes, "CDIO and the European project semester: A match for capstone projects?" in Proc. 11th Int. Conf. CDIO, 2015, pp. 1-14.
[28] M. F. Silva, B. Malheiro, P. Guedes, A. Duarte, and P. Ferreira, "Collaborative learning with sustainability-driven projects: A summary of the EPS@ISEP programme," Int. J. Eng. Pedagogy, vol. 8, no. 4, pp. 106-130, 2018.

[29] A. Brygider et al., "Design and development of a solar dryer for microalgae retrieval an EPS@ISEP 2013 spring project," in Proc. 3rd Int. Conf. Technol. Ecosyst. Enhanc. Multicult. (TEEM), Oct. 2015, pp. 529-536.

[30] A. Jenei et al., "Learning sustainability with EPS@ ISEP-Development of a water disinfection system," in Proc. 8th Int Symp. Project Approaches Eng. Educ. (PAEE), Jun. 2016, pp. 61-68.

[31] A. Fountain et al., "Learning sustainability with EPS@ISEPDevelopment of an insectarium," in Proc. 8th Int Symp. Project Approaches Eng. Educ. (PAEE), Jun. 2016, pp. 109-116.

[32] L. Borghuis et al., Escargot Nursery-An EPS@ISEP 2017 Project (Advances in Intelligent Systems and Computing), vol. 715, M. Auer, D. Guralnick, and I. Simonics, Eds. Braga, Portugal: Universidade do Minho, 2018, pp. 884-895.

[33] A. M. Llauradó et al., "Aquaponics system-An EPS@ISEP 2014 spring project," in Proc. 3rd Int. Conf. Technol. Ecosyst. Enhanc. Multicult. (TEEM), Oct. 2015, pp. 537-544.

[34] L. Armesto, P. Fuentes-Durá, and D. Perry, "Low-cost printable robots in education," J. Intell. Robot. Syst., vol. 81, no. 1, pp. 5-24, Jan 2016.

[35] P. Fuentes-Durá, F. G. Quevedo, and J. M. A. Fernández, "Innovación creativa: The NOMAD travelbox," in Proc. In-Red Congreso Nacional de Innovación Educativa y Docencia en Red, Valencia, Spain, 2015, pp. 1-15.

[36] J. Segalàs, M. E. Esbrí, and P. Benson, "European project Semester: 30 ECTS of PBL in sustainability with multicultural and multidisciplinary bachelor students groups," in Proc. 17th Int. Conf. Eng. Educ., Belfast, Ireland, 2011, pp. 1-9.

[37] K. F. Mulder, D. Ferrer, J. S. Coral, O. Kordas, E. Nikiforovich, and K. Pereverza, "Motivating students and lecturers for education in sustainable development," Int. J. Sustain. Higher Educ., vol. 16, no. 3, pp. 385-401, 2015.

Abel J. Duarte received the B.Sc. and five-year degrees in chemical engineering from Porto Polytechnic and the M.Sc. and Ph.D. degrees in chemistry from the University of Porto. He is an Adjunct Professor with the Department of Chemical Engineering, School of Engineering, Porto Polytechnic. His research interests include sustainable development, biochemical systems, and engineering education.

Benedita Malheiro received the five-year degree in electrical engineering and the M.Sc. and Ph.D. degrees in electrical and computer engineering from the University of Porto. She is an Adjunct Professor with the Electrical Engineering Department, School of Engineering, Porto Polytechnic, a Senior Researcher with the Robotics and Autonomous Systems Centre, INESC TEC, Porto, and a Coordinator of EPS@ISEP. Her research interests include distributed, dynamic, decentralized intelligent problem solving, data science, and engineering education. She is a member of AAAI, ACM, and APPIA.

Elisabet Arnó received the B.A. and Ph.D. degrees in English studies from the Universitat de Lleida, Spain. She is an Associate Professor of English for specific purposes with the Polytechnic University of Catalonia. Her research in applied linguistics is reflected in numerous publications and conference presentations. Since 2012, she has participated in the telecollaboration project Trans-Atlantic and Pacific Project, linking technical communication and translation lecturers and students from the U.S. and different European countries. 
Ignasi Perat is an Associate Professor with the Department of Electrical Engineering, Polytechnic University of Catalonia. Since 1989, he has been lecturing with the School of Engineering of Vilanova i la Geltrú, where he has been a member of the GAECE Research Group (Electronically Commutated Drives). He is currently taking part in numerous activities related to technology transfer and lifelong learning. He has published numerous specialized articles and has participated in different national and international conferences. He is currently the Director of the Master's degree in Rail Systems and Electric Drive.

Manuel F. Silva received the graduation, M.Sc., and Ph.D. degrees in electrical and computer engineering from the Faculty of Engineering, University of Porto, Portugal, in 1993, 1997, and 2005, respectively. He is currently an Adjunct Professor with the Department of Electrical Engineering, Institute of Engineering, Porto Polytechnic. His research focuses on modeling, simulation, robotics, multilegged walking robots, climbing robots, biological inspired robots, and education in engineering and control.

Pedro Fuentes-Durá received the Ph.D. degree in environmental engineering from the Universitat Politècnica de València, Spain, participating in several research projects. He trained as an Industrial Chemist with the University of Valencia. He is a Professor with the Nuclear and Chemical Engineering Department, Universitat Politècnica de València, where he has been the Head of International Relations and the Head of Business Relationship with the School of Design Engineering. He has participated in several projects of innovation in higher education and as a committee member in several international events in the framework of higher education. He is the Founder and the Co-Director of Valencia Global and the Coordinator of European Project Semester.
Pedro Guedes received the five-year degree in electrical and computer engineering from the University of Porto, Portugal, and the M.Sc. degree in systems control from the University of Technology of Compiègne, France. He is an Adjunct Professor with the Mathematics Department and a Researcher with Autonomous Systems Laboratory, School of Engineering, Porto Polytechnic.

Paulo Ferreira (M'11) received the five-year degree in electrical engineering and the M.Sc. degree in electrical and computer engineering from the University of Porto, Portugal. He is an Adjunct Professor with the Informatics Engineering Department, School of Engineering, Porto Polytechnic, Portugal, and an Invited Teacher with the University of Limoges, France. 